\title{
Prediction of the effect of temperature on impact damage in carbon/epoxy laminates
}

\author{
T. Gómez del Río, R. Zaera and C. Navarro \\ Department of Continuum Mechanics and Structural Analysis, Carlos III University of Madrid, \\ Avda. de la Universidad 30, 28911 Leganés, Madrid, Spain
}

\begin{abstract}
The effect of temperature on impact damage in Carbon Fiber Reinforced Plastic (CFRP) tape laminates produced by low velocity impact was studied by numerical simulations made to model drop weight tower impact tests on carbon/epoxy laminate composites. The damage model was implemented into a user subroutine of the finite element code ABAQUS. The model takes into account the thermal stresses resulting form the different thermal expansion coefficients in each ply of the laminate. The tests and simulations show how temperature affects the propagation of each damage mode. Matrix cracking and delamination are greatly affected by low temperature, while matrix crushing and fibre failure appear only in a small region at all the impact energies and test temperatures.
\end{abstract}

\section{INTRODUCTION}

Fibre reinforced plastics such as carbon/epoxi laminates are widely used for structural applications, in particular in the aerospace and aeronautical industries. During their operational life in these applications, the CFRP are subjected to low temperatures that could modify the mechanical properties of the material: cryogenic tanks, high-flying aircraft $\left(-60{ }^{\circ} \mathrm{C}\right)$ and spacecraft orbiting the Earth $\left(-150^{\circ} \mathrm{C}\right.$ when not exposed to solar radiation). At the same time, they can be exposed to impact loading. Unfortunately, carbon/epoxi laminates are very sensitive to low velocity impact, such as that of a drooped tool, which can damage the laminate and may result in catastrophic failure [1].

The behaviour of carbon fibre/epoxy laminates subjected to impact loads at room temperatures has been studied [2-7], but that of CFRPs under impact loading at low temperature is still an open question.

Considerable effort has gone into the numerical modelling of impact behaviour in composites [8-10]. Although different approaches to the analysis of impact events are available, finite element analysis based on accurate constitutive models provides the most detailed information on the spatial and temporal distribution of impact damage. The models differ in their formulation of the failure criteria used to signal the onset of damage in a ply, but most of the work published on this subject has neglected the interactions between the failure modes [1113]. To take into account matrix cracking and fibre failure as stress raisers at laminate interfaces, and the influence of fibre failure, matrix cracking and through-thickness compression in delamination, Hou et al. [12] coupled the Chang-Chang failure criteria [11] with the delamination criterion of Brewer and Lagace [14].

Here we evaluate the applicability of the Hou et al. criteria to predicting the nonpenetrating impact response of CFRP laminates at room and low temperatures, and to determine the influence of low temperature on impact damage, taking into consideration the thermal stresses in the laminate. 


\section{SOME EXPERIMENTAL EVIDENCE}

We impacted CFRP laminates at $20,-60$ and $-150^{\circ} \mathrm{C}$ using a drop weight tower with a climatic chamber. The specimens tested were $[0 / 90]_{3 S}$ and $[+45 /-45 / 0 / 90]_{S}$ plates of AS4/3501-6 tape (fibre volume fraction 0.6 ). The dimensions of the coupons were $80 \times 80 \mathrm{~mm}^{2}$, of $2.3 \mathrm{or} 1.6 \mathrm{~mm}$ thickness of the cross-ply and quasi-isotropic laminate. The impactor was a $3.62 \mathrm{~kg}$ steel rod with a spherically ended nose $20 \mathrm{~mm}$ in diameter, and impact energies ranged from 1 to $5 \mathrm{~J}$. CScan inspection of the impacted specimens showed a clear influence of temperature on the damage extension: At $-150{ }^{\circ} \mathrm{C}$ the damaged zone increased up to $50 \%$ compared to that at room temperature (Figure 1).
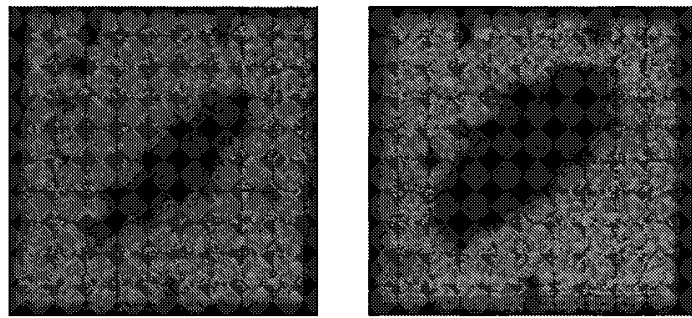

Figure 1. C-Scan image showing damage extension in the cross-ply laminate impacted at $4 \mathrm{~J} .20{ }^{\circ} \mathrm{C}$ (left) and $-150^{\circ} \mathrm{C}$ (right).

\section{NUMERICAL MODEL}

\subsection{Model Mesh}

The above-mentioned tests were simulated with ABAQUS/Explicit finite element code to determine the effect of the thermal conditions on the generation and propagation of the different types of damage. The finite element model was based on the experimental device. The element type is an 8-node solid element with one integration point. The laminate was modelled with one element per ply, and a refined mesh was used in the vecinity of the impact zone. Boundary conditions were imposed on some surface nodes to simulate clamping. For simplicity, the impactor was modelled as a rigid body. Contact was applied between the plate and the impactor, whose initial velocity was 0.71 to $1.82 \mathrm{~m} / \mathrm{s}$. The model is shown in Figure 2 .

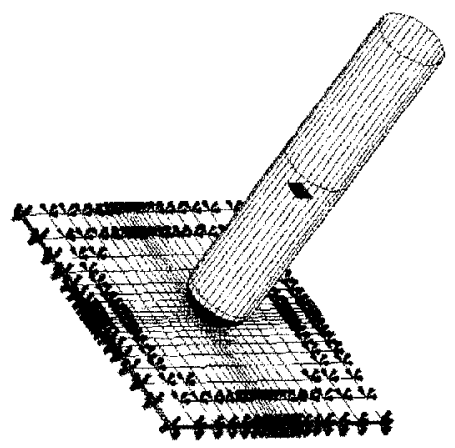

Figure 2. FEM model of the drop weight tower test. 


\subsection{Model material}

The composite failure material model used is based on the Hou et al. quadratic criteria [12]. It considers four failure modes, each linked to a damage factor. When the value of a factor equals one, some stresses are set to zero (Table 1). Before failure, the material is considered as orthotropic linear elastic. The constitutive thermoelastic equation, as well as the failure model was implemented into the user material subroutine of the ABAQUS code. The elastic properties of the ply (Figure 3) and the strength values of the failure model (Table 2) at the three testing temperatures were obtained from the literature [15-19 and from Hexcel Composites].

Table 1. Hou et al. failure model.

\begin{tabular}{|c|c|c|}
\hline Failure type & Damage factor equation & Stresses set to zero \\
\hline fibre failure & $e_{f}^{2}=\left(\frac{\sigma_{1}}{X_{T}}\right)^{2}+\left(\frac{\tau_{12}^{2}+\tau_{13}^{2}}{S_{f}^{2}}\right)^{2}$ & $\sigma_{1}, \sigma_{2}, \sigma_{3}, \tau_{12}, \tau_{23}, \tau_{13}$ \\
\hline matrix cracking (for $\sigma_{2}>0$ ) & $e_{m}^{2}=\left(\frac{\sigma_{2}}{Y_{T}}\right)^{2}+\left(\frac{\tau_{12}}{S_{12}}\right)^{2}+\left(\frac{\tau_{23}}{S_{m 23}}\right)^{2}$ & $\sigma_{2}, \tau_{12}$ \\
\hline matrix crushing (for $\left.\sigma_{2}<0\right)$ & $e_{m}^{2}=\left(\frac{\sigma_{2}}{Y_{T}}\right)^{2}+\left(\frac{\tau_{12}}{S_{12}}\right)^{2}+\left(\frac{\tau_{23}}{S_{m 23}}\right)^{2}$ & $\sigma_{2}$ \\
\hline delamination (for $\sigma_{3} \geq 0$ ) & $e_{d l}^{2}=\frac{1}{4}\left(\frac{\sigma_{2}}{S_{12}}\right)^{2}+\frac{Y_{C} \sigma_{2}}{4 S_{12}^{2}}-\frac{\sigma_{2}}{Y_{C}}+\left(\frac{\tau_{12}}{S_{12}}\right)^{2}$ & $\sigma_{3}, \tau_{23}, \tau_{13}$ \\
\hline
\end{tabular}

Table 2. AS4/3501-6 ply strengths at the three testing temperatures for the Hou et al. damage model.

\begin{tabular}{|c|c|r|r|r|r|r|r|r|r|}
\cline { 2 - 10 } \multicolumn{1}{c|}{} & \multicolumn{10}{|c|}{ Strengths (MPa) } \\
\hline Temperature & $X_{T}$ & $Y_{T}$ & $Y_{C}$ & $Z_{T}$ & $S_{l 2}$ & $S_{l 3}$ & $S_{f}$ & $S_{m 23}$ & $S_{l 23}$ \\
\hline $20^{\circ} \mathrm{C}$ & 2137 & 80 & 160 & 160 & 105 & 105 & 135 & 105 & 84 \\
\hline$-60^{\circ} \mathrm{C}$ & 2137 & 86 & 158 & 158 & 121 & 121 & 151 & 151 & 100 \\
\hline$-150^{\circ} \mathrm{C}$ & 2138 & 97 & 155 & 155 & 139 & 139 & 169 & 139 & 118 \\
\hline
\end{tabular}
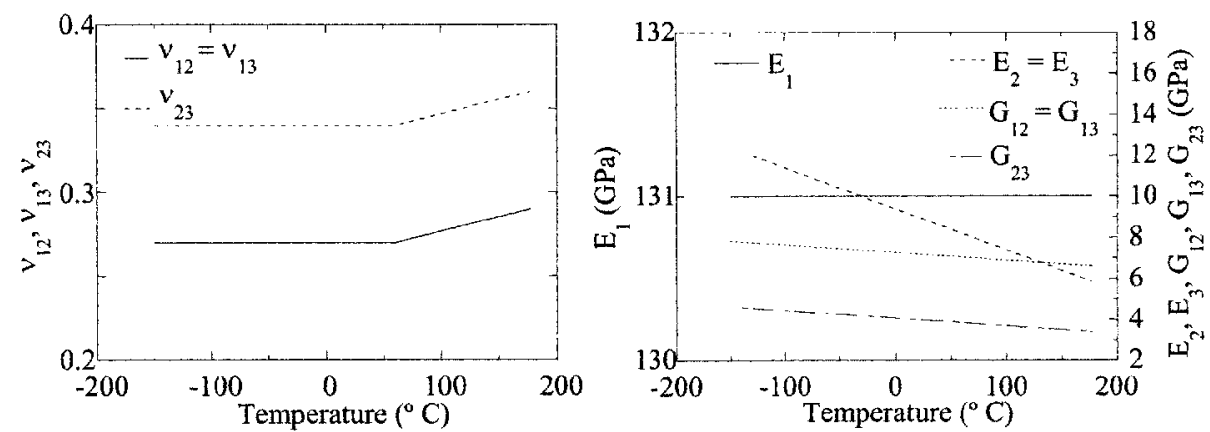

Figure 3.Variation with temperature of Poisson coefficient (left) and elastic moduli (right) of an AS4/3501-6 tape ply. 


\section{SIMULATION RESULTS}

The simulation of the impact problem permitted a detailed analysis of the generation and propagation of damage. Figures 5 to 8 show the evolution during impact of the four damage factors considered in the Hou et al. model $\left(e_{j}, e_{m}, e_{d}, e_{l}\right)$. The four corresponding contours are plotted on a quarter of the laminate mesh (Figure 4) at two different times of an 8 milisecond impact process. Matrix cracking and crushing start soon on the face impacted by the striker, due to the high local compression stresses. While crushing is confined to the upper face close to the contact surface, matrix cracking develops extensively in the lower plies under the tensile stress generated by the bending of the plate. These cracks propagate along the plies and throughthickness. Delamination occurs in the intermediate plies (layers subjected to high shear stresses), close to the impact zone due to the transverse and through-thickness tensile stress induced by contact, and also in the lower plies with the propagation of matrix cracking. Fibre fracture appears close to the contact zone and in the lower plies as a consequence of high in-plane stresses. This damage distribution, predicted by the numerical model, agrees with experimental observations of the specimens inspected after impact.
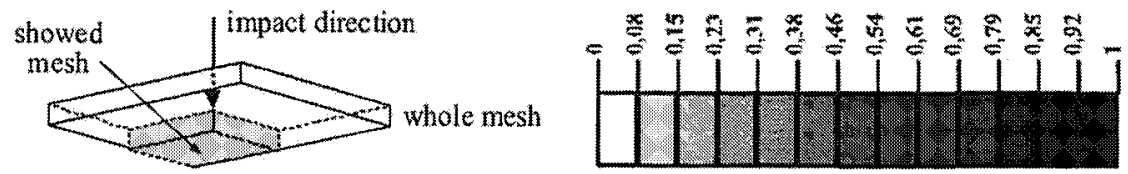

Figure 4. Left: mesh showed in Figures 5 to 10. Right: contour values for damage factors in Figures 5 to 10.
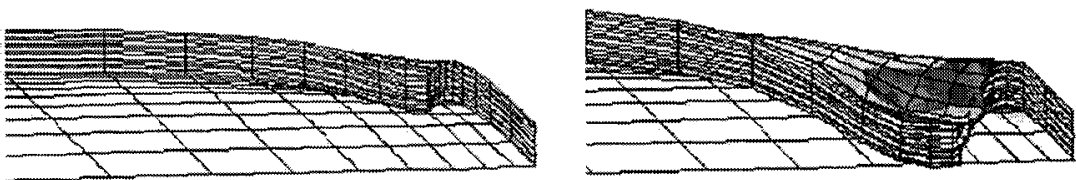

Figure 5. Fibre failure contours for a $6 \mathrm{~J}$ impact on a $[0 / 90]_{3 s}$ laminate at $20^{\circ} \mathrm{C}$. Left: $2 \mathrm{~ms}$. Right: $6 \mathrm{~ms}$.
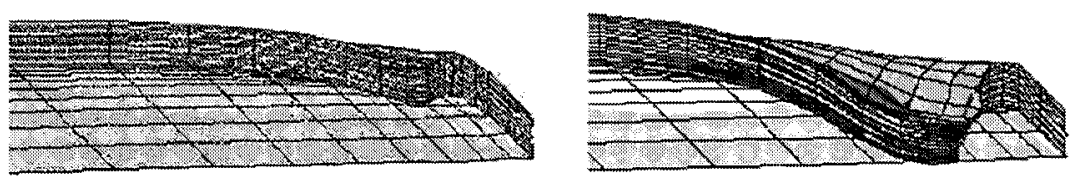

Figure 6. Matrix cracking contours for a $6 \mathrm{~J}$ impact on a $[0 / 90]_{3 \mathrm{~s}}$ laminate at $20^{\circ} \mathrm{C}$. Left: $2 \mathrm{~ms}$. Right: $6 \mathrm{~ms}$.
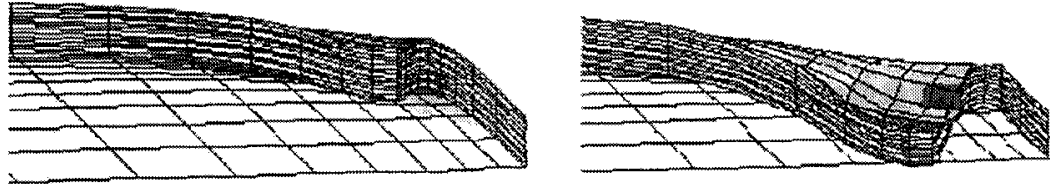

Figure 7. Matrix crushing contours for a $6 \mathrm{~J}$ impact on a $[0 / 90]_{3 \mathrm{~S}}$ laminate at $20^{\circ} \mathrm{C}$. Left: $2 \mathrm{~ms}$. Right: $6 \mathrm{~ms}$. 

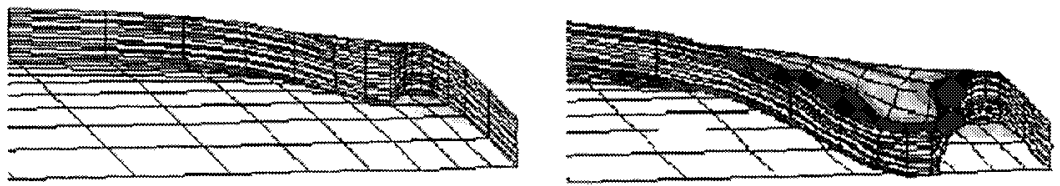

Figure 8. Delamination contours for a $6 \mathrm{~J}$ impact on a $[0 / 90]_{35}$ laminate at $20^{\circ} \mathrm{C}$. Left: 2 ms. Right: $6 \mathrm{~ms}$.

Once the material model showed its ability to predict damage generation and propagation in CFRP specimens subjected to low velocity impact, the effect of the low temperature was examined. The cooling process before impact was simulated with ABAQUS/Standard, and the subsequent impulsive load with ABAQUS/Explicit. Thermally induced stresses before impact affects damage factors, and although most are small, that corresponding to matrix cracking could be relatively high $\left(60 \%\right.$ of the critical value at $\left.-150^{\circ} \mathrm{C}\right)$. This means that matrix cracking develops easily when the specimen is impacted at low temperature (Figure 9). As matrix cracks precede delamination, the extension of this damage is also greater at low temperature, as is shown by the contours depicted in Figure 10.
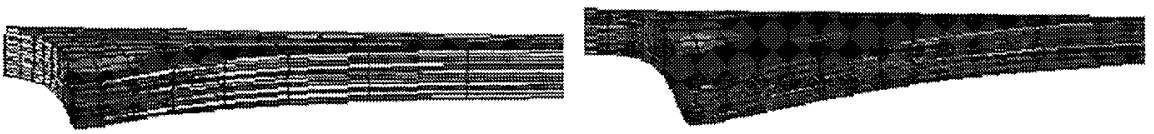

Figure 9. Final matrix cracking contours of a $[0 / 90]_{3 \mathrm{~S}}$ laminate impacted at $20^{\circ} \mathrm{C}$ (left) and $-150^{\circ} \mathrm{C}$ (right). Impact energy: $3 \mathrm{~J}$.
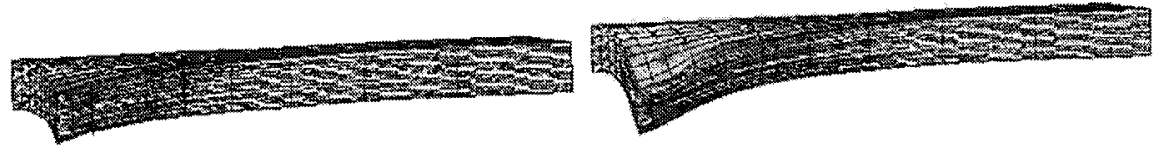

Figure 10. Final delamination contours of a $[0 / 90]_{3 S}$ laminate impacted at $20^{\circ} \mathrm{C}$ (left) and $-150{ }^{\circ} \mathrm{C}$ (right). Impact energy: $3 \mathrm{~J}$.

\section{CONCLUSIONS}

The Hou et al failure model for fiber-reinforced composite material was implemented into a commercial finite element code to predict the growth and extension of damage in CFRP laminates subjected to low velocity impact. The damage distribution predicted by the model agrees with the experimental results; failed fibres, matrix cracks and delaminated surfaces detected by inspection of the tested laminates were located in the same zones in the numerical model.

Low temperature has a marked effect on the failure of CFRP: both matrix cracking, due to the high in-plane thermally induced stresses, and delamination develop earlier during impact at low temperature and the damage extends more widely.

\section{Acknowledgements}

The authors are indebted to the Spanish Comisión Interministerial de Ciencia y Tecnologia (Project MAT-98/0273) for the financial support of this work. 


\section{References}

[1] Sun C.T. 4th Conference on Composite Materials: Testing and Design, ASTM STP-617-T Analytical method for evaluation of impact damage energy of laminated composites. ASTM STP 617 (1977), pp. 427-440.

[2] Cantwell W.J. and Morton J. The impact resistance of composite materials: a review. Composites, Volume (22) number 5, (1991), pp. 347-362.

[3]Abrate S. Impact on laminated composite materials. App. Mech. Rev., Volume 44 (1991), pp. $155-190$.

[4] Bradshaw J.C., Dorey G. and Sidney G.R. Impact resistance of carbon fibre reinforced plastics. Technical Report TR 72240 MOD, RAE (1972).

[5] Kirk J.R., Munro M. and Beaumont P.W.R. The fracture energy of hybrid carbon and glass fibre composites. J. Mat. Sci., Volume 13 (1978), pp. 2197-2204.

[5] Beaumont P.W.R. Fracture Mechanics: current status, future prospects, chapter of Fracture mechanics in fibrous composites, edited by R.A. Smith, Pergamon Press (1979), pp. 211-233.

[7] Cantwell W.J., Morton J. and Curtis, P. T. A study on the impact performance and subsequent 0-compression fatigue performance of non-woven and mix-woven composites. In J.Morton, editor Structural Impact and Crashworthiness. Elsevier Applied Science (1984), pp. $521-531$.

[8] Hallet S.R. and Ruiz C. Material Characterization Tests and Modelling of Carbon Fibre T300/914 at impact rates of strain.

J. Phys. IV (1997), pp. C3/465-470.

[9] Choi H.Y. and Chang F.K. A model for predicting damage in graphite/epoxy laminated composites resulting from low-velocity point impact. Journal of Composite Material. Volume 26, number 14 (1992), pp. 2134-2169.

[10] Vieira C.A. and Savi M.A. Modelling and simulation of delamination in composite materials. Journal of Strain Analysis, Volume 35, number 6 (2000), pp. 479-492.

[11] Chang F. and Chang K.A. A progressive damage model for laminated composites containing stress concentrations. J. Composite Materials, Volume 21 (1987), pp. 834-855.

[12] Hou J.P., Petrinic N., Ruiz C. and S.R. Hallet. Prediction of impact damage in composite plates. Comp. Struct. and Techn., Volume 60 (2000), pp. 273-281.

[13] Symons D.D. Impact damage tolerance of carbon fibre reinforced plastics. Ph.D. Thesis: Oxford University (1998).

[14] Brewer J.C. and Lagace P.A. Quadratic stress criterion for initiation of delamination. $J$. Composite Materials, Volume 22, number 12 (1988), pp. 1141-1155.

[15] Reed R.P. and Golda M. Cryogenic properties of unidirectional composites. Cryogenics, Volume 11 (1994), pp. 909-928.

[16] Aoki T,, Ishikawa T., Kumazawa H. and Morino Y. Mechanical behaviour of cf/polymer composite laminates under cryogenic environment. In ICCM 12, Volume V (1999).

[17] Cheng D.D.L. Carbon fiber composites. Edited by Butterworth-Heinemann (1994).

[18] Reed R.P. and Golda M. Cryogenic properties of unidirectional composites. Cryogenics, Volume 11 (1994), pp. 909-928.

[19] Cheng D.D.L. Carbon fiber composites. Edited by Butterworth-Heinemann (1994). 